\title{
A theoretical study of the parameters affecting the power delivery efficiency of an agricultural tractor
}

\author{
Nicolò Regazzi ${ }^{\text {a }}$, Mirko Maraldi ${ }^{a,},{ }^{,}$Giovanni Molari ${ }^{\mathrm{a}}$ \\ ${ }^{a}$ Department of Agricultural and Food Sciences (DISTAL), University of Bologna, Viale G. Fanin 50, 40127 Bologna, Italy
}

\begin{abstract}
:
Tractive efficiency is of major concern to agricultural tractors manufacturers, end-users and to society as well, both for economical and environmental reasons. In this article, a traction model of a whole vehicle is developed which accounts for the special features of a MFWD agricultural tractor.

The aim of the article was to identify the key design parameters affecting the power delivery efficiency of an agricultural tractor and to quantify their effect on the tractive performance. To this end, numerical simulations were performed varying several tractor design parameters. The results of the simulations were then analysed using a gradient-based method which allowed to identify the most influential design parameters. A regression surface for the estimation of the tractive efficiency as a function of the relevant tractor design parameters was used to approximate the results of the numerical simulations and a quantitative relation to calculate the optimal mass distribution in terms of power delivery efficiency is proposed.

Within the range of variation of the design parameters explored in this study, the maximum power delivery efficiency was found for a tractor having equal kinetic rolling radii of front and rear tyres, no lead of the front wheels and the centre of mass shifted towards the front axle. However, if the front tyres kinetic rolling radius becomes smaller than that of rear tyres and if there is lead of the front wheels, the tractor centre of mass has to be shifted towards the rear axle to attain the maximum overall traction efficiency.
\end{abstract}

Keywords: Power delivery efficiency; gradient-based method; optimal parameters; mass distribution; lead of the front wheels.

\footnotetext{
${ }^{*}$ Corresponding author.

E-mail address: mirko.maraldi@unibo.it (M. Maraldi).

Post-print. Full paper published in Biosystems Engineering.

Link to full paper: https://doi.org/10.1016/j.biosystemseng.2019.07.006
} 


\begin{tabular}{|c|c|c|}
\hline & Nomenclature & \\
\hline$B$ & Tractor wheelbase & {$[\mathrm{m}]$} \\
\hline$b_{f}$ & Width of the soil - front tyre contact surface & {$[\mathrm{m}]$} \\
\hline$b_{r}$ & Width of the soil - rear tyre contact surface & {$[\mathrm{m}]$} \\
\hline$c_{1}$ & Coefficient for the relative position of maximum radial stress & {$[-]$} \\
\hline$c_{2}$ & Coefficient for the relative position of maximum radial stress & {$[-]$} \\
\hline$c_{3}$ & Coefficient for rut recovery angle location & {$[-]$} \\
\hline$c_{f}$ & Soil cohesion at the front tyre & {$[\mathrm{Pa}]$} \\
\hline$c_{r}$ & Soil cohesion at the rear tyre & {$[\mathrm{Pa}]$} \\
\hline$F_{D P}$ & Drawbar pull & {$[\mathrm{N}]$} \\
\hline$H_{f}$ & Longitudinal force on front axle & {$[\mathrm{N}]$} \\
\hline$H_{r}$ & Longitudinal force on rear axle & {$[N]$} \\
\hline$h$ & Drawbar height & {$[\mathrm{m}]$} \\
\hline$j_{0, f}$ & Shearing deformation modulus at the front tyre & {$[\mathrm{m}]$} \\
\hline$j_{0, r}$ & Shearing deformation modulus at the rear tyre & {$[\mathrm{m}]$} \\
\hline$j_{f}$ & Shear displacement at the front tyre & {$[\mathrm{m}]$} \\
\hline$j_{r}$ & Shear displacement at the rear tyre & {$[\mathrm{m}]$} \\
\hline$K_{M}$ & Static mass distribution ratio & {$[-]$} \\
\hline$K_{P}$ & Pull distribution ratio & {$[-]$} \\
\hline$K_{W}$ & Front-to-rear ratio of kinetic rolling radii & {$[-]$} \\
\hline$k_{c, f}$ & Parameter related to soil cohesion at the front tyre & {$\left[\mathrm{N} \mathrm{m}^{-\mathrm{n}-1}\right]$} \\
\hline$k_{c, r}$ & Parameter related to soil cohesion at the rear tyre & {$\left[\mathrm{N} \mathrm{m} \mathrm{m}^{-\mathrm{n}-1}\right]$} \\
\hline$k_{\phi, f}$ & Parameter related to soil internal friction angle at the front tyre & {$\left[\mathrm{N} \mathrm{m}^{-\mathrm{n}-2}\right]$} \\
\hline$k_{\phi, r}$ & Parameter related to soil internal friction angle at the rear tyre & {$\left[\mathrm{N} \mathrm{m}^{-\mathrm{n}-2}\right]$} \\
\hline$L$ & Lead of the front wheels & {$[-]$} \\
\hline$l_{1}$ & Longitudinal distance between front axle and centre of gravity & {$[\mathrm{m}]$} \\
\hline$l_{2}$ & Longitudinal distance between rear axle and centre of gravity & {$[\mathrm{m}]$} \\
\hline$M_{e}$ & Engine torque at the flywheel & {$[\mathrm{Nm}]$} \\
\hline$M_{f}$ & Torque at the front axle & {$[\mathrm{Nm}]$} \\
\hline$M_{r}$ & Torque at the rear axle & {$[\mathrm{Nm}]$} \\
\hline$M_{t r}$ & Torque at the output shaft of the transmission & {$[\mathrm{Nm}]$} \\
\hline$n$ & Bekker sinkage exponent & {$[-]$} \\
\hline$r_{f}$ & Front tyre kinetic rolling radius & {$[\mathrm{m}]$} \\
\hline$r_{r}$ & Rear tyre kinetic rolling radius & {$[\mathrm{m}]$} \\
\hline$S$ & Tractor slip & {$[-]$} \\
\hline$s_{f}$ & Front wheel slip & {$[-]$} \\
\hline$S_{r}$ & Rear wheel slip & {$[-]$} \\
\hline$V_{f}$ & Vertical load on front axle & {$[\mathrm{N}]$} \\
\hline$V_{r}$ & Vertical load on rear axle & {$[\mathrm{N}]$} \\
\hline$v$ & Tractor speed & {$\left[\mathrm{m} \mathrm{s}^{-1}\right]$} \\
\hline$W$ & Tractor weight & {$[\mathrm{N}]$} \\
\hline
\end{tabular}




\begin{tabular}{|c|c|c|}
\hline$\beta_{i}$ & $i$-th coefficient of the regression function & [various] \\
\hline$\phi$ & Soil internal friction angle & [rad] \\
\hline$\eta_{M}$ & Motion efficiency & {$[-]$} \\
\hline$\hat{\eta}_{M}$ & Motion efficiency as a function of tractor design parameters & {$[-]$} \\
\hline$\eta_{S}$ & Slip efficiency & {$[-]$} \\
\hline$\hat{\eta}_{S}$ & Slip efficiency as a function of tractor design parameters & {$[-]$} \\
\hline$\eta_{T}$ & Power delivery efficiency & {$[-]$} \\
\hline$\hat{\eta}_{T}$ & $\begin{array}{l}\text { Power delivery efficiency as a function of tractor design } \\
\text { parameters }\end{array}$ & {$[-]$} \\
\hline$\eta_{t r}$ & Transmission efficiency & {$[-]$} \\
\hline$\eta_{\text {tractive }}$ & Tractive efficiency & {$[-]$} \\
\hline$\theta$ & Variable of integration for the stress functions & [rad] \\
\hline$\theta_{1, f}$ & Front wheel entry angle & [rad] \\
\hline$\theta_{1, r}$ & Rear wheel entry angle & [rad] \\
\hline$\theta_{2, f}$ & Front wheel rut recovery angle & [rad] \\
\hline$\theta_{2, r}$ & Rear wheel rut recovery angle & [rad] \\
\hline$\theta_{m, f}$ & Front wheel angle of maximum stress & [rad] \\
\hline$\theta_{m, r}$ & Rear wheel angle of maximum stress & {$[\mathrm{rad}]$} \\
\hline$\sigma_{f}$ & Front wheel normal stress & {$[\mathrm{MPa}]$} \\
\hline$\sigma_{r}$ & Rear wheel normal stress & {$[\mathrm{MPa}]$} \\
\hline$\tau_{d}$ & Transmission front axle lead ratio & {$[-]$} \\
\hline$\tau_{f}$ & Front wheel tangential stress & {$[\mathrm{MPa}]$} \\
\hline$\tau_{r}$ & Rear wheel tangential stress & {$[\mathrm{MPa}]$} \\
\hline$\tau_{t r}$ & Transmission gear ratio & {$[-]$} \\
\hline$\omega_{e}$ & Engine speed & {$\left[\mathrm{rad} \mathrm{s}^{-1}\right]$} \\
\hline$\omega_{f}$ & Front axle angular velocity & {$\left[\mathrm{rad} \mathrm{s}^{-1}\right]$} \\
\hline$\omega_{r}$ & Rear axle angular velocity & {$\left[\mathrm{rad} \mathrm{s}^{-1}\right]$} \\
\hline
\end{tabular}

\section{Introduction}

Tractive efficiency and fuel consumption of agricultural tractors are topics that have been receiving close attention recently, both for economical and for environmental reasons, and tractor manufacturers are devoting more attention and resources to the design of efficient products (Goering, 1992). The power delivery efficiency of a tractor during in-field operations depends on the performance of the tractor driveline and on how the tractor interacts with the soil; in turn, the efficiency of tyre-soil interaction depends on the design parameters of the tractor. Hence, understanding which are the keyparameters affecting the tractive efficiency and quantifying their role is of primary importance in this context. 
The efficiency of traction of agricultural vehicles has been mostly investigated experimentally. The influence of tyre size and inflation pressure, front-to-rear tyre inflation pressure ratio, kind of tyres, front ballasting and type of soil on the performance of agricultural tractors was investigated either by in-field tests (Bashford et al., 1985; Zoz \& Grisso, 2003; Stoilov \& Kostadinov, 2009; Molari et al., 2012, 2015; Damanauskas \& Janulevičius, 2015; Janulevičius et al., 2018) or using scaled tractor models (Gu \& Kushwaha, 1994). Tyre slip, tractive efficiency, fuel consumption and field productivity were the quantities over which data comparison was conducted. Results indicated that a lower tyre inflation pressure decreased fuel consumption and slip and that front ballasting also reduced slip in four-wheel drive tractors, but increased fuel consumption due to the greater overall tractor weight. In particular, Bashford et al. (1985) investigated the performance of a front wheel assist tractor as a function of mass distribution and peripheral speed ratio (a quantity related to the lead of the front wheels) by changing ballast distribution and front tyre size. In their study, bias-ply tyres were used and the peripheral speed ratio ranged from 0.97 to 1.13 (i.e. lead of the front wheels ranged from -0.03 to 0.13); optimal values for mass distribution and peripheral speed ratio were determined.

In the experimental studies performed so far, front ballasting was the method used to change the tractor static mass distribution and changing tyre inflation pressure and size was a method for changing both tyre rolling radii and the lead of the front wheels. In this respect, Janulevičius et al. (2017) showed how changes in tyres inflation pressure affect the lead of the front wheels of a mechanical front-wheel drive (MFWD) tractor. In their study, the amount of slip/skid of both the front and the rear wheels was experimentally determined for a tractor driven on a flat hard surface with no draft load. The procedure allowed determining the value of tyre inflation pressure ensuring acceptable values of lead of the front wheels for traction purposes. However, the studies presented in the literature do not completely clarify to what extent lead of the front wheels is beneficial or detrimental for tractive performance.

The reason for the choice of changing ballasting and tyre inflation pressure in the experimental procedures lies in the fact that these are the variables that tractor operators can control. However, such an experimental approach has some drawbacks: first of all, in many of the studies the influence of mass distribution on the tractive efficiency is not examined independently, since a mere change in front ballasting also changes the overall mass of the tractor; moreover, changing the tyre inflation pressure does not allow decoupling the effect of lead of the front wheels from that of front-to-rear tyre diameter ratio on the tractive performance; last, the range of variation of mass distribution, lead of the front wheels and tyre rolling radii that can be obtained is narrow. On the other hand, a theoretical study allows varying each tractor design parameter (e.g. mass distribution, front-to-rear rolling radii ratio, lead of the front wheels) as well as tractor operating conditions (e.g. ballasting, tyre inflation pressure, soil conditions) selectively and by a large amount.

Theoretical studies on the tractive efficiency of off-road vehicles were conducted following different approaches (Upadhyaya, 2009; Pichlmaier, 2012). The simplest is a purely phenomenological (empirical) approach (Freitag, 1966; Wismer \& Luth, 1973; Brixius, 1987; Al-Hamed et al., 1994), which relies on the computation of phenomenological quantities, such as the wheel mobility number and the wheel numeric, to predict tractor performance. However, as pointed out by Upadhyaya (Upadhyaya, 2009, p. 185), empirical methods are not very useful in improving tractors design or in dealing with new designs, since they do not highlight the underlying physics of the phenomena involved in traction.

Another approach used to develop models for theoretical studies is grounded on fundamental mechanics (Wong, 2010; Senatore \& Sandu, 2011a, b; Liang et al., 2014). Such an approach relies upon the study of the mechanical equilibrium of the tractor and on the modelling of the stresses developed during tyre-soil interaction. Therefore, it appears more suitable for a theoretical study aimed at quantifying the contribution of the different design parameters on the tractive efficiency of a tractor and is the one pursued in this article. 
Wong and Reece (1967a,b) and Wong (2010) treated in an extensive manner the efficiency of the interaction between the soil and a generic off-road vehicle by considering the cases of towed and driving wheels; however, vehicle wheels are considered separately from each other and the wheel slip is considered as an independent variable whose value is given a priori and not determined as a consequence of tractor operating conditions. Following the approach of Wong to the traction problem, Senatore \& Sandu $(2011 \mathrm{a}, \mathrm{b})$ proposed a model to study the tractive performance of an off-road vehicle as a whole and investigated the effects of torque distribution (between front and rear axles) and the role of the multipass effect on the tractive performance. The vehicle considered in their studies was isodiametric (i.e., equipped with the same tyres at both the front and the rear axles) and comprised a central differential to distribute torque between the front and the rear axle; tyre deformability was modelled as well. In a similar fashion, Liang et al. (2014) studied the influence of the vehicle mass distribution on the tractive performance of a four-wheel drive (4WD) lunar roving vehicle: an isodiametric vehicle with a locked 4WD driveline in which the front axle angular velocity was equal to that of the rear axle was considered.

Although tractive efficiency of vehicles has been quite extensively investigated through theoretical studies, the models proposed in the literature do not satisfactorily address the case of agricultural tractors. First, agricultural tractors are equipped with a different driveline, consisting of a torque splitting system between the front and the rear axles designed to have the front axle rotating at a different speed than the rear axle (front axle lead); moreover, agricultural tractors typically have a greater mass and can be non-isodiametric.

In this article, a traction model of a whole vehicle is developed which accounts for the special features of a MFWD agricultural tractor. In particular, a locked 4WD transmission system with front axle lead was modelled. The model was then used to investigate the effects of a complete set of design parameters on the power delivery efficiency of a tractor. To this end, the results of the numerical simulations conducted with the tractor model were analysed using a gradient-based method. The aim of this paper is to identify the key design parameters affecting the power delivery efficiency and to quantify their effect on the tractive performance.

\section{Materials and Methods}

\subsection{The tractor model}

A model of a 4WD tractor is developed in this study (Fig. 1). Differently from the models proposed in previous studies (Liang et al., 2014; Senatore \& Sandu, 2011b), the model developed in this article accounts for a non-isodiametric vehicle (i.e. tyres can be different from front to rear) and comprises a locked 4WD driveline with front axle lead, in order to model appropriately the driveline of most commercial agricultural tractors.

Contact stresses at the tyre-soil interface can be estimated either by using constitutive relations based on elastoplasticity and critical state soil mechanics (Upadhyaya, 2009; Upadhyaya et al., 2002; Yong et al., 1984; Baladi \& Rohani, 1984) or by employing semi-empirical equations (Bekker, 1969; Janosi \& Hanamoto, 1961; Upadhyaya et al., 1995; Senatore \& Sandu, 2011a,b; Liang et al., 2014). The former method for the estimation of the contact stresses appears more physically sound; however, it leads to more complex equations than the semi-empirical method. 


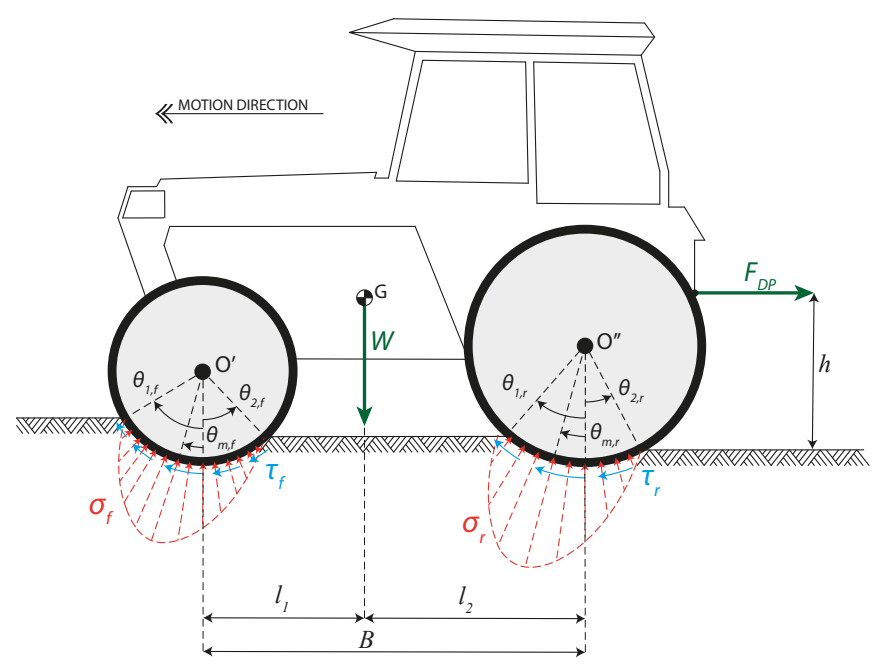

Fig. 1 - Model of the tractor and of the external loads acting on it.

Although the semi-empirical method is simpler, it requires the determination of several soil parameters; moreover, the validity of the hypotheses under which the stress formulations are derived is still of concern for the case of a deformable tyre moving on a deformable surface (Upadhyaya, 2009). Nevertheless, semi-empirical methods do not conceal the relevant mechanics involved in the description of agricultural tractors under working conditions, as reported by Upadhyaya (2009) which showed that this approach is quite accurate at predicting the experimental observations in terms of tractor performance. For this reason, the model is developed using semi-empirical equations for the estimation of the stresses at the tyre-soil interface.

Another key aspect is the modelling of the geometry of the tyre-soil contact surface. In this respect, some studies treated deformable tyres as rigid wheels having a diameter larger than the tyre overall diameter (Fujimoto, 1977; Perdok, 1978; Wong, 1989), while others (Schmid, 1995; Shmulevich \& Osetinsky, 2003) modelled the profile of the deformed tyre as a parabola. In the model developed in this article, tyre deformability is accounted for through the notion of kinetic rolling radius. The kinetic rolling radius is defined as the distance between the centre of the wheel and the resultant of the elementary tractive forces acting along the tyre-soil contact surface (Kiss, 2003); its value differs from that of the tyre radius (i.e. from that of half of the tyre overall diameter, ANSI/SAE S296.4, 1995). The geometry of the tyre-soil contact surface is not modelled directly, thus; constitutive equations for the normal and the tangential stresses developing at the tyre-soil interface are assumed, and the kinetic rolling radius is introduced as the parameter accounting for the location of the contact stresses. From a geometrical point of view, this corresponds to a contact surface between the soil and the tyre being, ideally, an arc of fixed width and radius equal to the tyres kinetic rolling radius. The multipass effect is not considered, since the model encompasses only the features that are necessary to highlight the influence of tractor design parameters on the tractive efficiency.

\subsubsection{Equilibrium of the tractor chassis and driveline model}

Assuming the tractor travelling at constant speed on a horizontal straight line, and assuming that the drawbar pull is along the longitudinal direction, the following equations hold (equilibrium of forces along the longitudinal direction; equilibrium of forces along the vertical direction; equilibrium of moments about the rear axle axis of rotation, Fig. 2): 


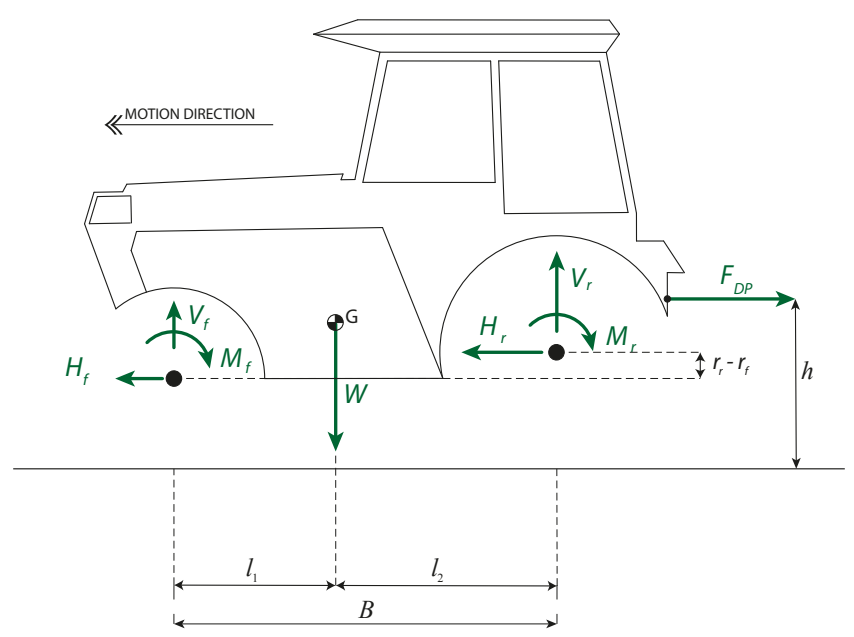

Fig. 2 - External loads acting on the tractor chassis.

$\left\{\begin{array}{l}F_{D P}=H_{f}+H_{r} \\ W=V_{f}+V_{r} \\ V_{f}\left(l_{1}+l_{2}\right)-W l_{2}+H_{f}\left(r_{r}-r_{f}\right)+M_{f}+M_{r}+F_{D P}\left(h-r_{r}\right)=0\end{array}\right.$,

where $H_{f}, H_{r}, V_{f}, V_{r}, M_{f}$ and $M_{r}$ are the forces and torques that the front and rear wheels transmit to the tractor chassis, while $W$ is the tractor weight and $F_{D P}$ is the drawbar pull (Fig. 2).

In addition, it is assumed that the chassis behaves as a rigid body, i.e. the distance between the front and the rear axle remains constant; hence, the following kinematic condition linking the slip of the front wheels $s_{f}$ to that of the rear wheels $s_{r}$ arises:

$\omega_{f} r_{f}\left(1-s_{f}\right)=\omega_{r} r_{r}\left(1-s_{r}\right)$

where $\omega_{f}$ and $\omega_{r}$ are the angular velocities of the front and rear wheels, respectively, and slip is defined in the usual manner (Wong, 2010):

$s_{i}=\frac{\omega_{i} r_{i}-v}{\omega_{i} r_{i}}$,

where $v$ is the speed of the tractor and $i=f, r$ generic subscripts for front and rear. The radii $r_{f}$ and $r_{r}$ are the kinetic rolling radii of the front and rear tyres, respectively.

In a MFWD driveline (Fig. 3a), the torque-splitting device that distributes the torque between the front and rear axles is constituted by a pair of meshing gears of different diameters; its transmission ratio determines the ratio between the angular velocity of the front axle and that of the rear axle, and ultimately the lead of the front axle. The input torque to the device is the torque at the output shaft of the transmission and the torque distribution between the front and the rear axle is not fixed a priori, but depends on the requests arising from the slipping tyre-soil contact at the front and at the rear axles.

The lead of the front wheels is defined as follows:

$L=\frac{\omega_{f} r_{f}-\omega_{r} r_{r}}{\omega_{r} r_{r}}=K_{W} \tau_{d}-1$ 
where $K_{W}=\frac{r_{f}}{r_{r}}$ is the front-to-rear ratio of kinetic rolling radii and $\tau_{d}$ is the transmission front axle lead ratio.

By introducing the notion of lead of the front wheels, Eq. (2) can be rephrased:

$$
S_{r}=(L+1) s_{f}-L
$$

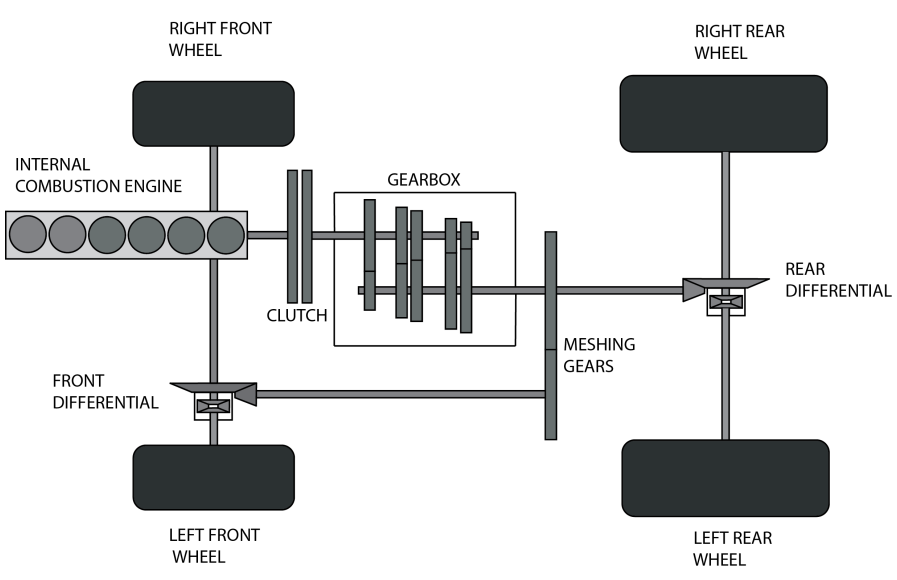

(a)

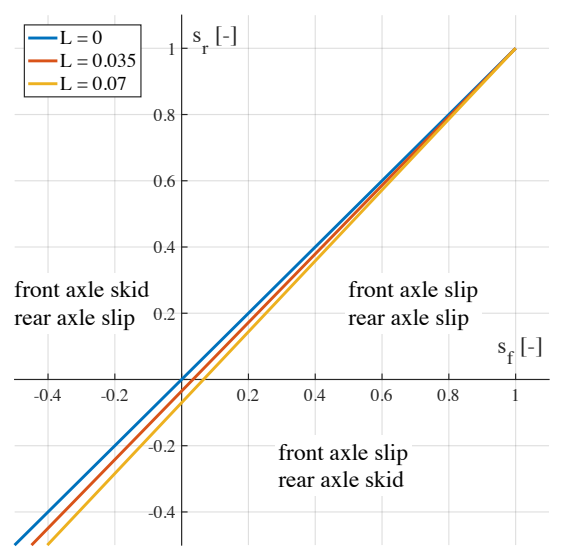

(b)

Fig. 3 - (a) Top view of a MFWD tractor driveline; (b) relationship between front wheel slip, rear wheel slip and lead of the front wheels.

Eq. (5) highlights the fact that the slip of the front wheels and that of the rear wheels are not independent from each other (Vantsevich, 2014; Janulevičius et al., 2017) and their values depend on the value of the lead of the front wheels (Fig. 3b). In turn, the lead of the front wheels depends (Eq. (4)) both on the transmission front axle lead ratio (a constructive parameter) and on the front-to-rear ratio of kinetic rolling radii, and is subject to change if tyres of different sizes are used, or if tyres inflation pressure changes.

Accounting for Eq. (4), the equations that govern the behaviour of the tractor driveline are the following:

$$
\left\{\begin{array}{l}
M_{t r}=M_{r}+\frac{L+1}{K_{w}} M_{f} \\
\omega_{f}=\frac{L+1}{K_{w}} \omega_{r} \\
M_{e}=\frac{M_{t r}}{\tau_{t r} \eta_{t r}} \\
\omega_{e}=\tau_{t r} \omega_{r}
\end{array}\right.
$$

where $M_{t r}$ is the torque at the transmission output shaft, $M_{e}$ the engine torque at the flywheel, which is a function of the engine angular velocity $\omega_{e}$ and of the engine load, $\tau_{t r}$ the transmission gear ratio at the current engaged gear and $\eta_{t r}$ the transmission efficiency. 


\subsubsection{Equilibrium of the wheels and constitutive equations for tyre-soil interaction}

Due to soil deformability and wheel sinkage into the soil, it is reasonable to assume (Wong, 2010) that the contact between the tyre and the soil (Fig. 4) starts at an entry angle $\theta_{1}$ and ends at a rut recovery angle $\theta_{2}$; moreover, the normal stresses $\sigma(\theta)$ and the tangential stresses $\tau(\theta)$, exerted by the soil on the tyre along their contact arc, are non-constant.

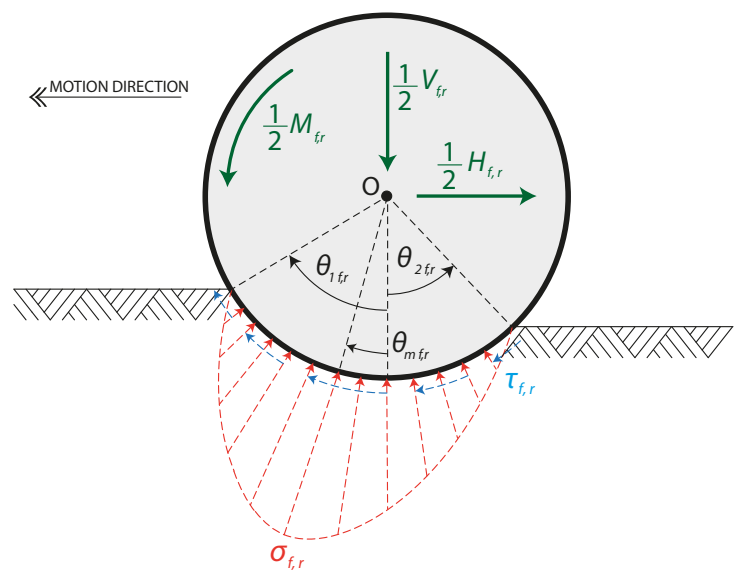

Fig. 4 - Forces acting on the front (subscript $f$ ) and rear (subscript $r$ ) wheels.

Assuming, for symmetry reasons, that the left part and the right part of the tractor behave in the same manner, the resulting equilibrium equations for one front wheel and for one rear wheel are (Fig. 4):

$$
\begin{aligned}
& \frac{1}{2} H_{f}=b_{f} r_{f} \int_{\theta_{2, f}}^{\theta_{1, f}}\left(\tau_{f} \cos \theta-\sigma_{f} \sin \theta\right) d \theta \\
& \left\{\frac{1}{2} V_{f}=b_{f} r_{f} \int_{\theta_{2, f}}^{\theta_{1, f}}\left(\tau_{f} \sin \theta+\sigma_{f} \cos \theta\right) d \theta\right. \\
& \frac{1}{2} M_{f}=b_{f} r_{f}^{2} \int_{\theta_{2, f}}^{\theta_{1, f}} \tau_{f} d \theta \\
& \left\{\begin{array}{l}
\frac{1}{2} H_{r}=b_{r} r_{r} \int_{\theta_{2, r}}^{\theta_{1, r}}\left(\tau_{r} \cos \theta-\sigma_{r} \sin \theta\right) d \theta \\
\frac{1}{2} V_{r}=b_{r} r_{r} \int_{\theta_{2, r}}^{\theta_{1, r}}\left(\tau_{r} \sin \theta+\sigma_{r} \cos \theta\right) d \theta \\
\frac{1}{2} M_{r}=b_{r} r_{r}^{2} \int_{\theta_{2, r}}^{\theta_{1, r}} \tau_{r} d \theta
\end{array}\right.
\end{aligned}
$$

where $b_{f}$ and $b_{r}$ are the width of the contact surfaces between the soil and the front and rear tyres, respectively. Tyre-soil interaction has been widely studied in the past by Wong \& Reece (1967a; 
1967b), Bekker (1969) and by Janosi \& Hamamoto (1961), among others. The formulations of the normal and tangential stresses developed at the tyre-soil interface provided in these studies are well established in the scientific community and commonly assumed as a basis for the development of whole-vehicle traction models. As it regards the normal stresses developed at the tyre-soil interface, the Bekker-Reece equation is assumed here (Bekker, 1969; Wong \& Reece, 1967a; Shibly et al., 2005; Senatore \& Sandu, 2011a; Liang et al., 2014):

$$
\begin{gathered}
\sigma_{f}(\theta)= \begin{cases}\left(\frac{k_{c, f}}{b_{f}}+k_{\phi, f}\right) r_{f}^{n}\left[\cos \left(\theta_{1, f}-\frac{\theta-\theta_{2, f}}{\theta_{m, f}-\theta_{2, f}}\left(\theta_{1, f}-\theta_{m, f}\right)\right)-\cos \left(\theta_{1, f}\right)\right]^{n}, & \text { for } \theta_{2, f} \leq \theta \leq \theta_{m, f} \\
\left(\frac{k_{c, f}}{b_{f}}+k_{\phi, f}\right) r_{f}^{n}\left[\cos (\theta)-\cos \left(\theta_{1, f}\right)\right]^{n}, & \text { for } \theta_{m, f}<\theta \leq \theta_{1, f}\end{cases} \\
\sigma_{r}(\theta)= \begin{cases}\left(\frac{k_{c, r}}{b_{r}}+k_{\phi, r}\right) r_{r}^{n}\left[\cos \left(\theta_{1, r}-\frac{\theta-\theta_{2, r}}{\theta_{m, r}-\theta_{2, r}}\left(\theta_{1, r}-\theta_{m, r}\right)\right)-\cos \left(\theta_{1, r}\right)\right]^{n}, & \text { for } \theta_{2, r} \leq \theta \leq \theta_{m, r} \\
\left(\frac{k_{c, r}}{b_{r}}+k_{\phi, r}\right) r_{r}^{n}\left[\cos (\theta)-\cos \left(\theta_{1, r}\right)\right]^{n}, & \text { for } \theta_{m, r}<\theta \leq \theta_{1, r},\end{cases}
\end{gathered}
$$

where $k_{c, i}$ and $k_{\phi, i}, i=f, r$, are soil parameters and $n$ is the Bekker sinkage exponent. For the tangential stresses, the Janosi-Hanamoto equation is assumed (Janosi \& Hanamoto, 1961; Senatore \& Sandu, 2011a; Liang et al., 2014):

$$
\begin{gathered}
\tau_{f}(\theta)=\left[c_{f}+\sigma_{f}(\theta) \tan \phi\right]\left(1-\exp \left(-\frac{j_{f}}{j_{0, f}}\right)\right) \\
\tau_{r}(\theta)=\left[c_{r}+\sigma_{r}(\theta) \tan \phi\right]\left(1-\exp \left(-\frac{j_{r}}{j_{0, r}}\right)\right),
\end{gathered}
$$

where $\phi, c_{i}$ and $j_{0, i}, i=f, r$, are soil parameters and $j_{i}, i=f, r$, is the soil shear displacement under the tyres. In Eqs. (9) - (12), the angle at which the normal stress is maximum is (Wong \& Reece, 1967a):

$$
\begin{gathered}
\theta_{m, f}=\left(c_{1}+c_{2}\left|s_{f}\right|\right) \theta_{1, f}, \\
\theta_{m, r}=\left(c_{1}+c_{2}\left|s_{r}\right|\right) \theta_{1, r},
\end{gathered}
$$

while the values of the angle $\theta_{2}$ are computed as follows (Liang et al., 2014): 


$$
\begin{aligned}
& \theta_{2, f}=c_{3} \theta_{1, f} \\
& \theta_{2, r}=c_{3} \theta_{1, r}
\end{aligned}
$$

where $c_{1}, c_{2}$ and $c_{3}$ are constants. The shear displacement of the soil is computed as follows (Wong \& Reece, 1967a):

$$
\begin{aligned}
& j_{f}=r_{f}\left[\theta_{1, f}-\theta-\left(1-s_{f}\right)\left(\sin \left(\theta_{1, f}\right)-\sin (\theta)\right)\right] \\
& j_{r}=r_{r}\left[\theta_{1, r}-\theta-\left(1-s_{r}\right)\left(\sin \left(\theta_{1, r}\right)-\sin (\theta)\right)\right] .
\end{aligned}
$$

\subsubsection{Power delivery efficiency}

The power delivery efficiency is defined as follows (Wong, 2010):

$$
\eta_{T}=\frac{F_{D P} v}{M_{e} \omega_{e}}=\eta_{t r} \eta_{S} \eta_{M} .
$$

Eq. (16) shows that the power delivery efficiency is the ratio of the drawbar power to the input power provided by the engine, and can be split into the product of three contributions (see Appendix A for details):

- the transmission efficiency $\eta_{t r}$

- the slip efficiency $\eta_{S}$

- the motion efficiency $\eta_{M}$.

Another widely used measure of the efficiency of traction is the tractive efficiency (ANSI/ASAE S296.4, 1995), which is expressed by (Wong, 2010):

$\eta_{\text {tractive }}=\eta_{S} \eta_{M}=\frac{\eta_{T}}{\eta_{t r}}$

A comparison between Eqs. (16) and (17) shows that the power delivery efficiency and the tractive efficiency differ only by the transmission efficiency term. The efficiency of the transmission is mainly influenced by the transmission type, the number of engaged meshing gears, the engine load and the engine angular velocity; however, since tractors tend to operate within a narrow engine regime range and assuming a constant load, for the sake of simplicity and without loss of generality, the transmission efficiency was considered constant in this study (Schreiber, 2006). As a consequence, the qualitative results obtained for the power delivery efficiency in this paper also apply to the tractive efficiency.

The slip efficiency appearing in Eqs. (16) - (17) depends on the slip of the front and of the rear axles and for a two-axle tractor takes the form (Appendix A):

$$
\eta_{S}=1-\frac{s_{f}\left(1-s_{r}\right)-\left(s_{f}-s_{r}\right) K_{P}}{\left(1-s_{r}\right)-\left(s_{f}-s_{r}\right) K_{P}},
$$


where

$$
s=\frac{s_{f}\left(1-s_{r}\right)-\left(s_{f}-s_{r}\right) K_{P}}{\left(1-s_{r}\right)-\left(s_{f}-s_{r}\right) K_{P}}
$$

is defined as the vehicle slip and $K_{P}=\frac{H_{r}}{F_{D P}}$ is the pull distribution factor.

The motion efficiency in Eqs. (16) - (17) accounts for the efficiency in converting the driving torque on the wheels into drawbar force and, accounting for the driveline system modelled in this article, is given by (Appendix A):

$$
\eta_{M}=\frac{H_{f}(L+1)+H_{r}}{\frac{M_{f}}{r_{f}}(L+1)+\frac{M_{r}}{r_{r}}} .
$$

\subsubsection{Solution algorithm}

For a given tractor configuration, a given value of $F_{D P}$ and given soil parameters, the model described in Sections. 2.1.1 - 2.1.3 allows prediction of the power delivery efficiency. Indeed, substituting Eqs. (7) - (8) into Eq. (1) and accounting for Eq. (5), the following system of equations is obtained:

$$
\left\{\begin{array}{l}
F_{D P}=2 b_{f} r_{f} \int_{\theta_{2, f}}^{\theta_{1, f}}\left(\tau_{f} \cos \theta-\sigma_{f} \sin \theta\right) d \theta+2 b_{r} r_{r} \int_{\theta_{2, r}}^{\theta_{1,}}\left(\tau_{r} \cos \theta-\sigma_{r} \sin \theta\right) d \theta \\
W=2 b_{f} r_{f} \int_{\theta_{2, f}}^{\theta_{1,}}\left(\tau_{f} \sin \theta+\sigma_{f} \cos \theta\right) d \theta+2 b_{r} r_{r} \int_{\theta_{2, r}}^{\theta_{1, r}}\left(\tau_{r} \sin \theta+\sigma_{r} \cos \theta\right) d \theta \\
2 b_{f} r_{f}\left(l_{1}+l_{2}\right) \int_{\theta_{2, f}}^{\theta_{1, f}}\left(\tau_{f} \sin \theta+\sigma_{f} \cos \theta\right) d \theta+2 b_{f} r_{f}\left(r_{r}-r_{f}\right) \int_{\theta_{2, f}}^{\theta_{1, f}}\left(\tau_{f} \cos \theta-\sigma_{f} \sin \theta\right) d \theta+2 b_{f} r_{f}^{2} \int_{\theta_{2, f}}^{\theta_{1, f}} \tau_{f} d \theta+2 b_{r} r_{r}^{2} \int_{\theta_{2,}}^{\theta_{1, r}} \tau_{r} d \theta-W l_{2}+F_{D P}\left(h-r_{r}\right)=0 \\
s_{r}=(L+1) s_{f}-L .
\end{array}\right.
$$

Assuming the constitutive equations (9) - (15), the system (21) is a set of four algebraic integral equations in the following four unknowns:

$$
\left\{s_{f} ; s_{r} ; \theta_{1, f} ; \theta_{1, r}\right\}
$$

The system of equations was solved using the Trust Region Dogleg Algorithm (MATLAB®, Mathworks, Inc., MA, USA) and the Simpson's algorithm to evaluate the integrals.

From the values of the quantities in (22), Eqs. (7)-(8) allow calculation of $H_{f}, H_{r}, V_{f}, V_{r}, M_{f}$ and $M_{r}$. Then, the slip efficiency and the motion efficiency can be determined through Eqs. (18) and (20) and the power delivery efficiency through Eq. (16). 


\subsection{Gradient-based method for the analysis of the influence of the tractor design parameters on the power delivery efficiency}

A complete set of simulations was performed with the tractor model developed in Sect. 2.1 according to the algorithm described in Section 2.1.4. The baseline for the analysis was a generic row-crop tractor (Table 1) working on LETE sand soil (Table 2). The drawbar pull was kept constant and set at the value that maximised the power delivery efficiency for the baseline configuration. The following tractor design parameters were varied with respect to the baseline in the simulations:

- the static mass distribution $K_{M}=\frac{l_{1}}{B}$

- the wheelbase $B$

- the front-to-rear ratio of kinetic rolling radii $K_{W}$

- the lead of the front wheels $L$

- the drawbar height $h$

The other tractor parameters were kept constant. The intervals of variation of the variable parameters and the values of the constant parameters are listed in Table 3.

For each variable parameter, the interval of variation was divided into eight steps; therefore, a total of $8^{5}$ simulations were performed over the parameter domain

$$
\Omega=K_{M} \times B \times K_{W} \times L \times h
$$

which was discretised as a regular grid. For each simulation, the slip efficiency, the motion efficiency and the power delivery efficiency were calculated and taken as the quantities upon which the performance of a tractor configuration was evaluated.

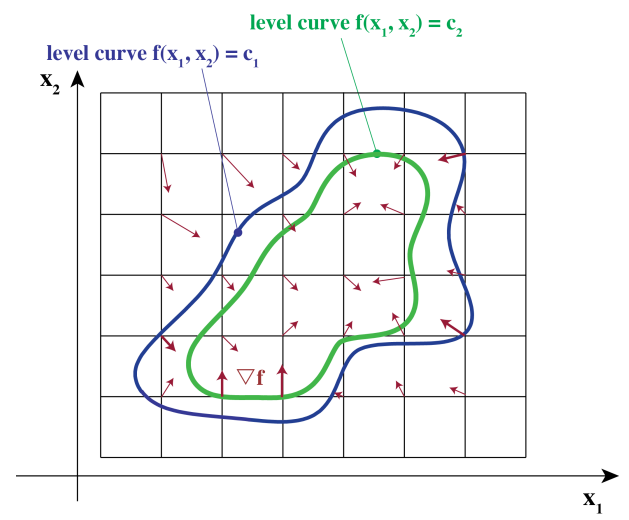

Fig. 5 - Example of the gradient analysis for a function of two variables. The domain is discretised in 56 points. The gradient is computed at the inner nodes. The direction of the gradient is perpendicular to the level curves and may vary from node to node.

A gradient-based method (Fig. 5) was implemented to evaluate if a given variable had an influence on the tractive performance. Indeed, if $f\left(x_{1}, x_{2}, \ldots, x_{n}\right)$ is a function of several variables, the gradient $\nabla f$ is a vector normal to the level curves of $f$ and is invariant under coordinate transformation (i.e. it does not depend on the coordinate system). The direction cosines of $\nabla f$ must be zero as the gradient is normal to the level surface; therefore, if $\nabla f$ is always perpendicular to a given coordinate, that coordinate has no influence at all on $f$. 
For the scope of the analysis, the computed efficiencies $\eta_{S}, \eta_{M}$ and $\eta_{T}$ were regarded as functions of five variables:

- $\hat{\eta}_{S}=\hat{\eta}_{S}\left(K_{M}^{*}, B^{*}, K_{W}^{*}, L^{*}, h^{*}\right)$

- $\hat{\eta}_{M}=\hat{\eta}_{M}\left(K_{M}^{*}, B^{*}, K_{W}^{*}, L^{*}, h^{*}\right)$

- $\hat{\eta}_{T}=\hat{\eta}_{T}\left(K_{M}^{*}, B^{*}, K_{W}^{*}, L^{*}, h^{*}\right)$

The circumflex above each symbol in (23) indicates that the quantities are computed at a fixed value of $F_{D P}$. The five variables are the scaled static mass distribution ratio, wheelbase, front-to-rear ratio of kinetic rolling radii, lead of the front wheels and drawbar height, obtained by taking the difference between the value of the variable and its mean value, and dividing it by half the range of the variable:

$$
\begin{gathered}
K_{M}^{*}=\frac{K_{M}-K_{M}^{\text {med }}}{\frac{1}{2}\left(K_{M}^{\max }-K_{M}^{\mathrm{min}}\right)}, B^{*}=\frac{B-B^{\text {med }}}{\frac{1}{2}\left(B^{\max }-B^{\mathrm{min}}\right)}, K_{W}^{*}=\frac{K_{W}-K_{W}^{\text {med }}}{\frac{1}{2}\left(K_{W}^{\max }-K_{W}^{\mathrm{min}}\right)}, \\
L^{*}=\frac{L-L^{\text {med }}}{\frac{1}{2}\left(L^{\max }-L^{\min }\right)}, h^{*}=\frac{h-h^{\text {med }}}{\frac{1}{2}\left(h^{\max }-h^{\min }\right)} .
\end{gathered}
$$

The scaling operation allows to refer all the variable parameters to a normalised scale and thus enables a direct comparison between the different variables. As a result, the functions in (23) are mapped onto the 5-dimensional, bi-unit domain:

$$
\Omega^{*}=[-1 ; 1] \times[-1 ; 1] \times[-1 ; 1] \times[-1 ; 1] \times[-1 ; 1] .
$$

The gradients of $\hat{\eta}_{S}, \hat{\eta}_{M}$ and $\hat{\eta}_{T}$ were then calculated at any inner point of the discretised domain $\Omega^{*}$ using a central difference scheme to evaluate each of the partial derivatives which constitute the gradient. The direction cosines of the gradients along the directions identified by the five variable parameters were plotted to determine the degree of influence of each tractor design parameter on the tractive performance. The least relevant design parameters were ruled out from the subsequent analysis.

\subsection{Regression surface for evaluating the influence of the relevant tractor design parameters on the power delivery efficiency}

To depict in a concise manner the results of the simulations performed for different values of the tractor design parameters and to evaluate the degree of influence of the relevant design parameters on the power delivery efficiency, the results of the numerical simulations in terms of $\hat{\eta}_{S}, \hat{\eta}_{M}$ and $\hat{\eta}_{T}$ were fitted with a polynomial regression surface. The regression surface accounted only for the relevant design parameters emerging from the gradient analysis and was kept at the lowest possible degree that allowed describing the observed trends. The least square method was used to determine the values of the regression surface coefficients. 


\begin{tabular}{l|c|}
\hline \multicolumn{2}{|l|}{$\begin{array}{l}\text { Table 1 - Tractor parameters for the } \\
\text { baseline configuration. }\end{array}$} \\
\hline Parameter & value \\
\hline$W$ & $87.2 \mathrm{kN}$ \\
$r_{r}$ & $0.900 \mathrm{~m}$ \\
$b_{r}$ & $0.750 \mathrm{~m}$ \\
$b_{f}$ & $0.600 \mathrm{~m}$ \\
$\eta_{t r}$ & 0.867 \\
$K_{M}$ & 0.580 \\
$B$ & $2.88 \mathrm{~m}$ \\
$K_{W}$ & 0.780 \\
$L$ & $6.59 \times 10^{-2}$ \\
$h$ & 0.560 \\
\hline
\end{tabular}

\begin{tabular}{|c|c|}
\hline Parameter & value/range \\
\hline$W$ & $87.2 \mathrm{kN}$ \\
\hline$r_{r}$ & $0.900 \mathrm{~m}$ \\
\hline$b_{r}$ & $0.750 \mathrm{~m}$ \\
\hline$b_{f}$ & $0.600 \mathrm{~m}$ \\
\hline$\eta_{t r}$ & 0.867 \\
\hline$F_{D P}$ & $27.5 \mathrm{kN}$ \\
\hline$K_{M}$ & {$[0.3 ; 0.8]$} \\
\hline$B$ & {$[2.5 ; 3.5] \mathrm{m}$} \\
\hline$K_{W}$ & {$[0.7 ; 1]$} \\
\hline$L$ & {$[0 ; 0.07]$} \\
\hline$h$ & {$[0.3 ; 0.7] \mathrm{m}$} \\
\hline
\end{tabular}

\begin{tabular}{|c|c|}
\hline Parameter & value \\
\hline$c_{1}$ & 0.200 \\
\hline$c_{2}$ & 0.300 \\
\hline$c_{3}$ & -0.125 \\
\hline$c_{f}$ & $0.900 \mathrm{kPa}$ \\
\hline$c_{r}$ & $0.900 \mathrm{kPa}$ \\
\hline$j_{0, f}$ & $11.5 \times 10^{-3} \mathrm{~m}$ \\
\hline$j_{0, r}$ & $11.5 \times 10^{-3} \mathrm{~m}$ \\
\hline$k_{c, f}$ & $1.560 \times 10^{5} \mathrm{~N} \mathrm{~m}^{-\mathrm{n}-1}$ \\
\hline$k_{c, r}$ & $1.560 \times 10^{5} \mathrm{~N} \mathrm{~m}^{-\mathrm{n}-1}$ \\
\hline$k_{\phi, f}$ & $4.53 \times 10^{6} \mathrm{~N} \mathrm{~m}^{-\mathrm{n}-2}$ \\
\hline$k_{\phi, r}$ & $4.53 \times 10^{6} \mathrm{~N} \mathrm{~m}^{-\mathrm{n}-2}$ \\
\hline$n$ & 0.806 \\
\hline$\phi$ & $0.550 \mathrm{rad}$ \\
\hline
\end{tabular}

\begin{tabular}{|c|c|}
\hline Parameter & value \\
\hline$W$ & $72.4 \mathrm{kN}$ \\
\hline$K_{M}$ & 0.550 \\
\hline$B$ & $2.63 \mathrm{~m}$ \\
\hline$r_{r}$ & $0.825 \mathrm{~m}$ \\
\hline$K_{W}$ & 0.788 \\
\hline$b_{r}$ & $0.591 \mathrm{~m}$ \\
\hline$b_{f}$ & $0.479 \mathrm{~m}$ \\
\hline$L$ & $1.260 \times 10^{-2}$ \\
\hline$h$ & $0.450 \mathrm{~m}$ \\
\hline$\eta_{t r}$ & 0.867 \\
\hline$c_{1}$ & 0.455 \\
\hline$c_{2}$ & 0.290 \\
\hline$c_{3}$ & -0.125 \\
\hline$c_{f}$ & $40.6 \mathrm{kPa}$ \\
\hline$c_{r}$ & $40.6 \mathrm{kPa}$ \\
\hline$j_{0, f}$ & $88.6 \times 10^{-3} \mathrm{~m}$ \\
\hline$j_{0, r}$ & $88.6 \times 10^{-3} \mathrm{~m}$ \\
\hline$k_{c, f}$ & $7.62 \times 10^{5} \mathrm{~N} \mathrm{~m}^{-\mathrm{n}-1}$ \\
\hline$k_{c, r}$ & $7.62 \times 10^{5} \mathrm{~N} \mathrm{~m}^{-\mathrm{n}-1}$ \\
\hline$k_{\phi, f}$ & $1.838 \times 10^{6} \mathrm{~N} \mathrm{~m}^{-\mathrm{n}-2}$ \\
\hline$k_{\phi, r}$ & $1.838 \times 10^{6} \mathrm{~N} \mathrm{~m}^{-\mathrm{n}-2}$ \\
\hline$n$ & 1.160 \\
\hline$\phi$ & $0.733 \mathrm{rad}$ \\
\hline
\end{tabular}




\section{Results and Discussion}

\subsection{Preliminary validation of the tractor model and efficiency curves predicted by the model}

The curves of $\eta_{S}, \eta_{M}$ and $\eta_{T}$ were determined through a series of numerical simulations performed at different values of the drawbar pull (Fig. 6). The tractor model was preliminary validated against experimental results obtained from drawbar tests performed on a MFWD row-crop tractor working on tilled loam soil (Mattetti et al., 2018). The tractor and soil parameters used for the model validation are listed in Table 4. Fig. 6a shows that the model is able to accurately reproduce the experimental observations $\left(\mathrm{R}^{2}=0.93\right)$.

Fig. $6 \mathrm{~b}$ shows the trend of the motion, slip and power delivery efficiencies as functions of the drawbar pull for the baseline configuration (row crop tractor working on LETE sand soil): if the drawbar pull increases, the slip efficiency decreases, while the motion efficiency increases; consequently, the power delivery efficiency increases, reaches its maximum value and then decreases. The maximum value of $\eta_{T}$ is reached at $11.2 \%$ of tractor slip, a result which is in agreement with the experimental observations reported in the literature (Wong, 2010). The model also predicts that there is a maximum value of the drawbar pull (vertical solid line in Fig. 6b) above which the tractor is not able to operate, i.e. the power delivery efficiency drops to zero. Fig. $6 \mathrm{~b}$ shows that for the baseline configuration the

maximum efficiency is reached approximately at $\frac{F_{D P}}{W}=0.31$, that is $F_{D P} \cong 27.5 \mathrm{kN}$. The result is slightly lower than the experimental observations reported in Zoz \& Grisso (2003); the difference may be due to the fact that Zoz \& Grisso data refer to tractors run over Lon's tilled soil, and not LETE sand soil.

\subsection{Determination of the tractor design parameters having an influence on the power delivery efficiency}

The application of the gradient-based method for the determination of the influence of the different design parameters on the power delivery efficiency requires the analysis of the direction cosines of $\nabla \hat{\eta}_{S}, \nabla \hat{\eta}_{M}$ and $\nabla \hat{\eta}_{T}$ reported in Fig. 7 for all the simulations performed. From the figure, it can be observed that the power delivery efficiency mainly depends on the mass distribution $K_{M}$, the front-torear ratio of kinetic rolling radii $K_{W}$ and the lead of the front wheels $L$; indeed, the direction cosines of $\nabla \hat{\eta}_{T}$ (Fig. 7a) along $h$ and $B$ remain close to zero for all the simulations performed. This means that (Section 2.2) changing the value of these parameters does not substantially affect the value of $\hat{\eta}_{T}$. Moreover, the signs of the direction cosines of $\nabla \hat{\eta}_{T}$ indicate that $\hat{\eta}_{T}$ depends monotonically on $K_{W}$ and non-monotonically on $K_{M}$ and on $L$. This means that, within the domain of variation of the design parameters, $\hat{\eta}_{T}$ has a maximum value: this value can be the optimum set of tractor design parameters that maximises the power delivery efficiency. The analysis of the direction cosines of $\nabla \hat{\eta}_{S}$ (Fig. 7b) leads to the same considerations with respect to the slip efficiency $\hat{\eta}_{s}$, whereas as it regards the motion efficiency $\hat{\eta}_{M}$ (Fig. 7c), the lead of the front wheels $L$ also has a limited effect on its value. 


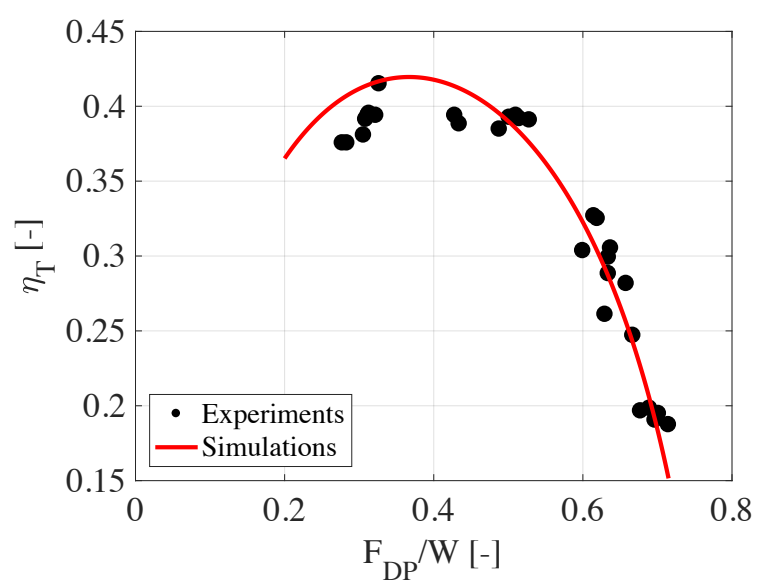

(a)

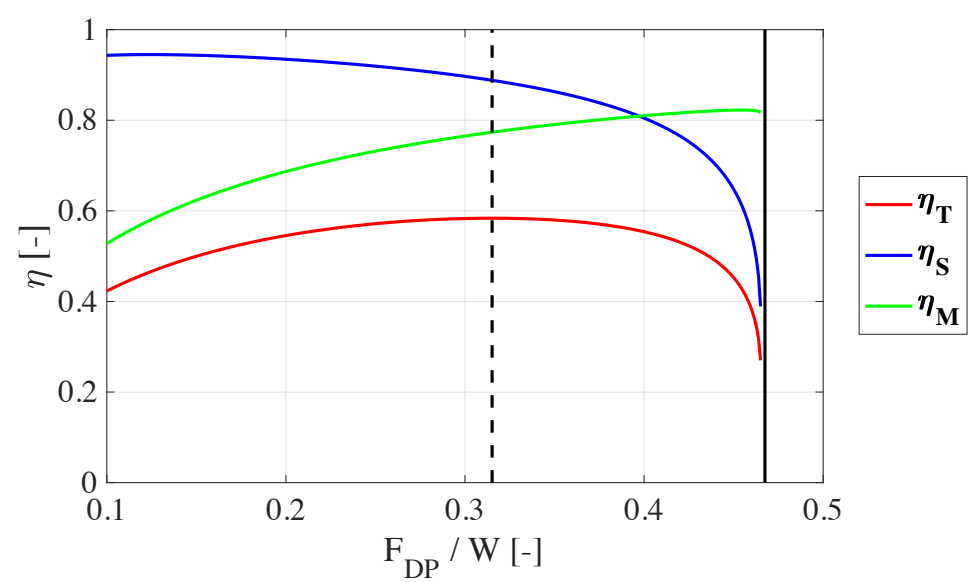

(b)

Fig. 6 - a) Comparison between experimental results and predicted power delivery efficiency according to the model developed in Section 2.1 (row-crop tractor working on tilled loam soil, Table 4). b) Efficiency curves as resulting from numerical simulations for the case of a row-crop tractor (Table 1) working on LETE sand soil (Table 2); the vertical dashed line marks the value of $F_{D P} / W$ corresponding to the maximum power delivery efficiency, while the vertical solid line marks the maximum attainable value of $F_{D P} / W$.

\subsection{Optimal values of the tractor design parameters}

The gradient analysis showed that within the tractor parameters range explored in this study, $\hat{\eta}_{T}$ depends monotonically on $K_{W}$ and non-monotonically on $K_{M}$ and on $L$ (Fig. 7). For this reason, the regression surface used to approximate the results of the numerical simulations is a polynomial of the second order in $K_{M}$ and $L$ and of the first order in $K_{W}$. For the sake of simplicity, the same function prototype was used for the regression models of $\hat{\eta}_{S}$ and of $\hat{\eta}_{M}$.

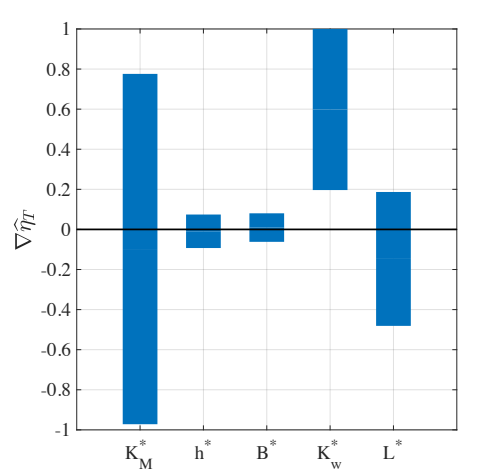

(a)

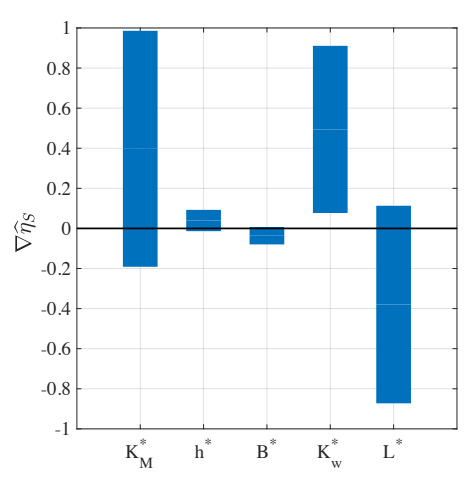

(b)

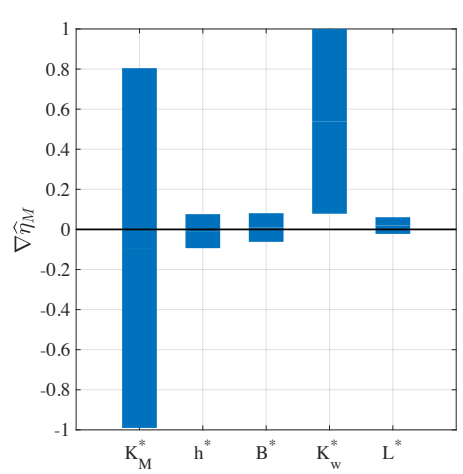

(c)

Fig. 7 - Direction cosines of the gradient of a) the power delivery efficiency; b) the slip efficiency; and c) the motion efficiency with respect to the scaled variable parameters. Each direction cosine refers to a tractor design parameter among those under investigation. For each plot, the vertical bar encloses the values of the direction cosines of the gradient calculated for all the simulations performed. Simulations refer to a generic row-crop tractor (Table 3) working on LETE sand soil (Table 2). 
The most generic polynomial having the required properties is:

$$
\hat{\eta}_{i}\left(K_{M}, K_{W}, L\right)=\alpha_{1}^{i}+\alpha_{2}^{i} K_{M}+\alpha_{3}^{i} L+\alpha_{4}^{i} K_{W}+\alpha_{5}^{i} K_{M}^{2}+\alpha_{6}^{i} L^{2}+\alpha_{7}^{i} K_{M} K_{W}+\alpha_{8}^{i} K_{M} L+\alpha_{9}^{i} K_{W} L,
$$

where $i=S, M, T$. The values of the regression surfaces coefficients and the fitting accuracy of Eq. (24) are listed in Table 5. The values of $\mathrm{R}^{2}$ reported in the table show that Eq. (24) can accurately approximate the results of the numerical simulations in terms of $\hat{\eta}_{S}, \hat{\eta}_{M}$ and $\hat{\eta}_{T}$.

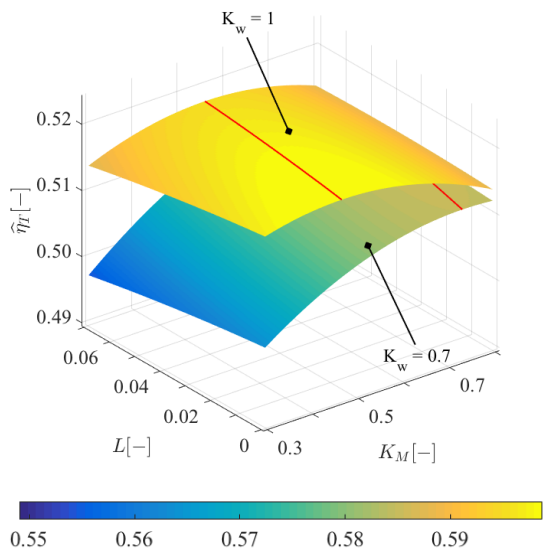

(a)

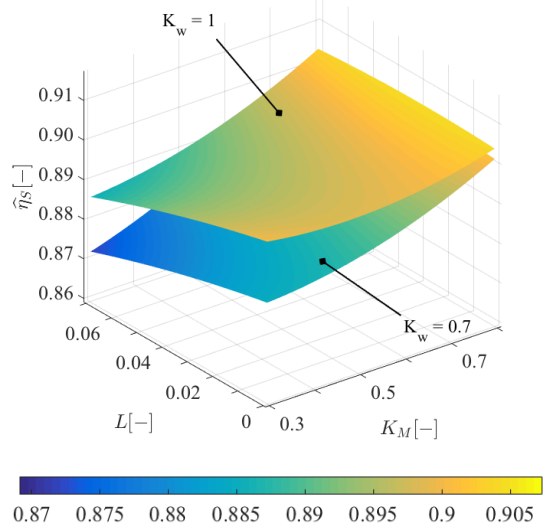

(b)

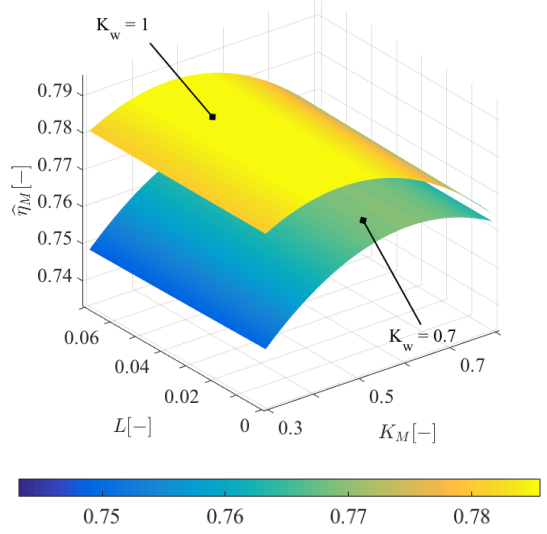

(c)

Fig. 8 - Effects of $K_{M}, L$, and $K_{W}$ on: a) $\hat{\eta}_{T}$; b) $\hat{\eta}_{S}$; and c) $\hat{\eta}_{M}$ for fixed working conditions. Simulations refer to a generic row-crop tractor (Table 3) working on LETE sand soil (Table 2). In a), the red lines are the ridgelines of the surfaces.

The plot of the regression surface in Fig. 8b shows that the highest values of the slip efficiency $\hat{\eta}_{S}$ are reached for a tractor having equal kinetic rolling radii of the front and rear tyres and a high value of $K_{M}$. Within the range of design parameters explored in this study, $\hat{\eta}_{S}$ ranged from 0.869 to 0.907 . Consistently with the analysis of Section 3.2, Fig. 8c shows that the motion efficiency $\hat{\eta}_{M}$ is substantially independent of $L$. Similarly to the case of $\hat{\eta}_{S}$, the maximum of $\hat{\eta}_{M}$ is reached for a tractor having equal kinetic rolling radii of the front and rear tyres; however, the value of $K_{M}$ that maximises the motion efficiency is closer to 0.5 in this case. Within the range of design parameters explored in this study, $\hat{\eta}_{M}$ ranged from 0.743 to 0.786 .

Table 5 - Coefficient values and fitting accuracy for the regression surfaces (Eq. (24)).

$\begin{array}{ccccccccccc} & \alpha_{1} & \alpha_{2} & \alpha_{3} & \alpha_{4} & \alpha_{5} & \alpha_{6} & \alpha_{7} & \alpha_{8} & \alpha_{9} & R^{2} \\ \hat{\eta}_{T} & 0.403 & 0.307 & -0.164 & 0.172 & -0.114 & -0.517 & -0.201 & 0.283 & -0.022 & 0.986 \\ \hat{\eta}_{S} & 0.834 & 0.034 & -0.202 & 0.077 & 0.053 & -0.705 & -0.085 & 0.397 & -0.077 & 0.985 \\ \hat{\eta}_{M} & 0.581 & 0.379 & -0.053 & 0.162 & -0.196 & 0.037 & -0.194 & 0.031 & 0.043 & 0.975\end{array}$

Within the range of design parameters explored in this study, $\hat{\eta}_{T}$ ranged from 0.549 to 0.599 . The maximum value of $\hat{\eta}_{T}$ (Figs. 8a and 9) is reached for a tractor having $K_{W}=1, K_{M}=0.46$ and $L=0$. Moreover, there is an optimal mass distribution that maximises the power delivery efficiency (red 
ridgelines in the plots in Figs. 8a and 9); the value of such optimal mass distribution is not fixed, but depends on the values of the lead of the front wheels and of the front-to-rear ratio of kinetic rolling radii. Indeed, by taking the partial derivative of the regression polynomial for $\hat{\eta}_{T}$ (Eq. (24)) with respect to $K_{M}$ and setting it to zero, the following equation for the optimal mass distribution is obtained:

$K_{M, o p t}=\frac{-\alpha_{2}-\alpha_{7} K_{W}-\alpha_{8} L}{2 \alpha_{5}}$

Within the range of the design parameters explored in this study, the optimal mass distribution ranges from 0.46 to 0.80 depending on the values of $K_{W}$ and $L$ (Fig. 9).

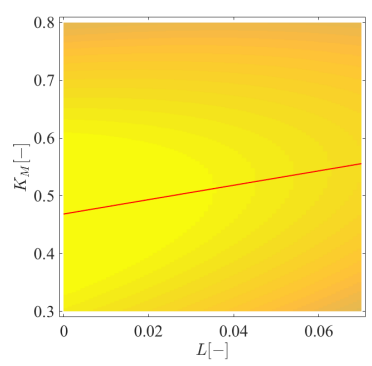

(a)

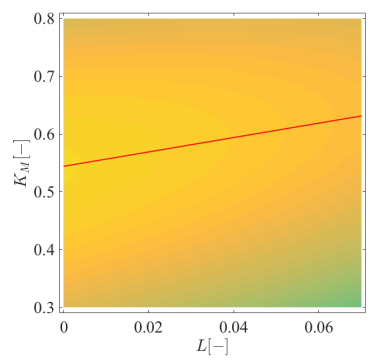

(b)

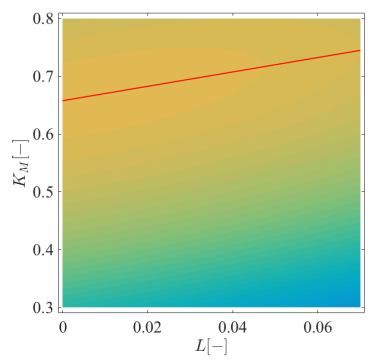

(c)

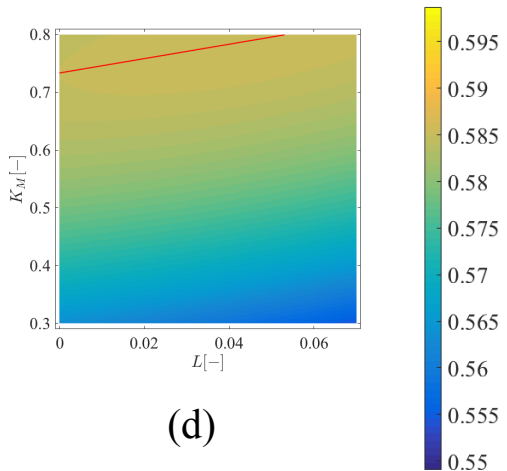

(d)

Fig. 9 - Heatmaps of $\hat{\eta}_{T}$ as a function of $L$ and $K_{M}$ for different values of the front-to-rear ratio of kinetic rolling radii: a) $K_{W}=1$; b) $K_{W}=0.91$; c) $K_{W}=0.79$; and d) $K_{W}=0.7$. Simulations refer to a generic row-crop tractor (Table 3) working on LETE sand soil (Table 2). The red lines are the lines of maximum efficiency for given value of $K_{W} \cdot$

\section{Conclusions}

The article aimed to identify the key design parameters that have an influence on the tractive performance of a MFWD agricultural tractor. To overcome the intrinsic limitations connected with an experimental study, a theoretical model was developed which allows varying independently and by a large amount each tractor design parameter. The model can be further extended to incorporate variables that tractor operators can change, like tyre inflation pressure.

The trend of the power delivery efficiency as a function of the drawbar pull and of the tractor slip predicted by the model was found to be in agreement with the experimental observations reported in the literature. Through a gradient-based method it was possible to determine that, among those under investigation (static mass distribution, wheelbase, front-to-rear ratio of kinetic rolling radii, lead of the front wheels and drawbar location), the most relevant tractor design parameters are the static mass distribution, the front-to-rear ratio of kinetic rolling radii and the lead of the front wheels.

Within the range of variation of the design parameters explored in this study, the maximum power delivery efficiency was found for a tractor having no lead of the front wheels, equal kinetic rolling radii of the front and rear tyres and the centre of mass shifted towards the front axle (mass distribution: $46 \%$ on the rear; $54 \%$ on the front). However, the optimal mass distribution may change considerably if the front-to-rear ratio of kinetic rolling radii and the lead of the front wheels are different from their optimal values. Importantly, these parameters may be subjected to additional design constraints arising, 
for example, from the steering kinematics of the tractor and from driveability considerations. The simulations performed in this study show that if the front-to-rear ratio of kinetic rolling radii decreases (i.e. the front tyre kinetic rolling radius becomes smaller than that of the rear tyre) the power delivery efficiency decreases. Results also showed that if the lead of the front wheels increases, in order to restore the maximum tractive efficiency the tractor centre of mass should be shifted rearwards. This is due to the fact that the presence of lead of the front wheels forces the slip of the front wheels to be greater to that of the rear wheels. As a result, in this cases the optimal configuration was obtained with the centre of mass closer to the rear axle than to the front axle.

The present study highlights that the key tractor design parameters cannot be considered unrelated from one another, because their interplay is crucial to the determination of the tractive efficiency. A theoretical model can be a useful tool in this respect, since all the relevant parameters affecting tractive efficiency can be analysed in a systematic and coherent manner. 


\section{References}

Al-Hamed, S. A., Grisso, R. D., Zoz, F. M., \& Von Bargen, K. (1994). Tractor performance spreadsheet for radial tires. Computers and Electronics in Agriculture, 10(1), 45-62.

ANSI/SAE S296.4 (1995). General terminology for traction of agricultural tractors, self-propelled implements, and traction and transport devices. St. Joseph, MI: American Society of Agricultural Engineers (ASAE).

Baladi, G. Y., \& Rohani, B. (1984). Development of a soil-wheel interaction model. In Proc. 8th Intl. Conf. ISTVS, 33-59.

Bashford, L. L., Woerman, G. R., \& Shropshire, G. J. (1985). Front wheel assist tractor performance in two and four-wheel drive modes. Transactions of the ASAE, 28(1), 23-0029.

Bekker, M. G. (1969). Introduction to Terrain-vehicle Systems. Ann Arbor, MI: University of Michigan Press.

Brixius, W. W. (1987). Traction prediction equations for bias ply tires. ASAE paper 87-1622. St. Joseph, MI: American Society of Agricultural Engineers.

Damanauskas, V., \& Janulevičius, A. (2015). Differences in tractor performance parameters between single-wheel 4WD and dual-wheel 2WD driving systems. Journal of Terramechanics, 60, 6373.

Freitag, D. R. (1966). A dimensional analysis of the performance of pneumatic tires on clay. Journal of Terramechanics, 3(3), 51-68.

Fujimoto, Y. (1977). Performance of elastic wheels on yielding cohesive soils. Journal of Terramechanics, 14(4), 191-210.

Goering, C. E. (1992). Engine and Tractor Power (3rd ed.). St. Joseph, MI: American Society of Agricultural Engineers (ASAE).

Gu, Y., \& Kushwaha, R. L. (1994). Dynamic load distribution and tractive performance of a model tractor. Journal of Terramechanics, 31(1), 21-39.

Janosi, Z., \& Hanamoto, B. (1961). The analytical determination of drawbar pull as a function of slip for tracked vehicles in deformable soils. In Proc. of 1st Int. Conf. of ISTVS. Turin, 1961.

Janulevičius, A., Pupinis, G., Lukštas, J., Damanauskas, V., \& Kurkauskas, V. (2017). Dependencies of the lead of front driving wheels on different tire deformations for a MFWD tractor. Transport, 32(1), 23-31.

Janulevičius, A., Damanauskas, V., \& Pupinis, G. (2018). Effect of variations in front wheels driving lead on performance of a farm tractor with mechanical front-wheel-drive. Journal of Terramechanics, 77, 23-30.

Kiss, P. (2003). Rolling radii of a pneumatic tyre on deformable soil. Biosystems Engineering, 85(2), $153-161$.

Liang, Z., Gao, H., Ding, L., Deng, Z., \& Qu, J. (2014). Analysis of driving efficiency for LRV wheels using forced-slip method. Advances in Space Research, 54(10), 2122-2130.

Mattetti, M., Varani, M., Paolini, F., \& Molari, G. (2018). Tractive performance of Trelleborg PneuTrac tyres. Manuscript in preparation.

Molari, G., Bellentani, L., Guarnieri, A., Walker, M., \& Sedoni, E. (2012). Performance of an agricultural tractor fitted with rubber tracks. Biosystems Engineering, 111(1), 57-63.

Molari, G., Mattetti, M., \& Walker, M. (2015). Field performance of an agricultural tractor fitted with rubber tracks on a low trafficable soil. Journal of Agricultural Engineering, 46(4), 162-166.

Perdok, U. D. (1978). A prediction model for the selection of tyres for towed vehicles on tilled soil. Journal of Agricultural Engineering Research, 23(4), 369-383. 
Pichlmaier, B. (2012). Traktionsmanagement für Traktoren (Doctoral thesis). München, Germany: Technischen Universität München.

Schmid, I. C. (1995). Interaction of vehicle and terrain results from 10 years research at IKK. Journal of Terramechanics, 32(1), 3-26.

Schreiber, M. (2012). Kraftstoffverbrauch beim Einsatz von Ackerschleppern im besonderen Hinblick auf die CO2-Emissionen (Doctoral thesis). Stuttgart, Germany: Universität Hohenheim.

Senatore, C., \& Sandu, C. (2011a). Off-road tire modeling and the multi-pass effect for vehicle dynamics simulation. Journal of Terramechanics, 48(4), 265-276.

Senatore, C., \& Sandu, C. (2011b). Torque distribution influence on tractive efficiency and mobility of off-road wheeled vehicles. Journal of Terramechanics, 48(5), 372-383.

Shibly, H., Iagnemma, K., \& Dubowsky, S. (2005). An equivalent soil mechanics formulation for rigid wheels in deformable terrain, with application to planetary exploration rovers. Journal of Terramechanics, 42(1), 1-13.

Shmulevich, I., \& Osetinsky, A. (2003). Traction performance of a pushed/pulled drive wheel. Journal of Terramechanics, 40(1), 33-50.

Stoilov, S., \& Kostadinov, G. D. (2009). Effect of weight distribution on the slip efficiency of a fourwheel-drive skidder. Biosystems Engineering, 104(4), 486-492.

Upadhyaya, S. K. (2009). Part V: Traction Prediction Equations, of Chapter 2: Traction Mechanics. In Advances in Soil Dynamics Volume 3: 161-186. S. K. Upadhyaya, W. J. Chancellor, J. V. Perumpral, D. Wulfsohn, and T. R. Way, eds. St. Joseph, MI: ASABE.

Upadhyaya, S. K., Rosa, U. A., \& Wulfsohn, D. (2002). Application of the finite element method in agricultural soil mechanics. In Advances in Soil Dynamics Volume 2: 117-153. S. K. Upadhyaya, W. J. Chancellor, J. V. Perumpral, R. L. Schafer, W. R. Gill, and G. E. Vanden Berg, eds. St. Joseph, MI: ASAE.

Vantsevich, V. V. (2014). Vehicle systems: coupled and interactive dynamics analysis. Vehicle System Dynamics, 52(11), 1489-1516.

Wismer, R. D., \& Luth, H. J. (1973). Off-road traction prediction for wheeled vehicles. Journal of Terramechanics, 10(2), 49-61.

Wong, J. Y., \& Reece, A. R. (1967a). Prediction of rigid wheel performance based on the analysis of soil-wheel stresses, Part I. Performance of driven rigid wheels. Journal of Terramechanics, 4(1), 81-98.

Wong, J. Y., \& Reece, A. R. (1967b). Prediction of rigid wheel performance based on the analysis of soil-wheel stresses, Part II. Performance of towed rigid wheels. Journal of Terramechanics, 4(2), 7-25.

Wong, J. Y. (1989). Terramechanics and Off-road Vehicles. Amsterdam: Elsevier.

Wong, J. Y. (2010). Terramechanics and Off-road Vehicle Engineering (2nd ed.). Amsterdam: Elsevier.

Yong, R. N. (1984). Track-soil interaction. Journal of Terramechanics, 21(2), 133-152.

Zoz, F. M., \& Grisso, R. D. (2003). Traction and tractor performance. ASAE Distinguished Lecture Series. Tractor Design No. 27. St. Joseph, MI: ASAE. 


\section{Appendix A. Derivation of the expressions for the slip efficiency and for the motion efficiency of a two-axle wheel-drive vehicle}

\begin{tabular}{lll}
\multicolumn{1}{c}{ Appendix Nomenclature } & {$[\mathrm{N}]$} \\
$F_{D P}$ & Drawbar pull & {$[\mathrm{N}]$} \\
$H_{f}$ & Longitudinal force on front axle & {$[\mathrm{N}]$} \\
$H_{r}$ & Longitudinal force on rear axle & {$[-]$} \\
$K_{P}$ & Pull distribution ratio & {$[-]$} \\
$K_{W}$ & Front-to-rear ratio of kinetic rolling radii & {$[-]$} \\
$L$ & Lead of the front wheels & {$[\mathrm{Nm}]$} \\
$M_{e}$ & Engine torque at the flywheel & {$[\mathrm{Nm}]$} \\
$M_{f}$ & Torque at the front axle & {$[\mathrm{Nm}]$} \\
$M_{r}$ & Torque at the rear axle & {$[\mathrm{m}]$} \\
$r_{f}$ & Front tyre kinetic rolling radius & {$[\mathrm{m}]$} \\
$r_{r}$ & Rear tyre kinetic rolling radius & {$[-]$} \\
$s$ & Tractor slip & {$[-]$} \\
$s_{f}$ & Front wheel slip & {$[-]$} \\
$s_{r}$ & Rear wheel slip & {$\left[\mathrm{m} \mathrm{s}{ }^{-1}\right]$} \\
$v$ & Tractor speed & {$[-]$} \\
$\eta_{M}$ & Motion efficiency & {$[-]$} \\
$\eta_{S}$ & Slip efficiency & {$[-]$} \\
$\eta_{T}$ & Power delivery efficiency & {$[-]$} \\
$\eta_{t r}$ & Transmission efficiency & {$[-]$} \\
$\tau_{d}$ & Transmission front axle lead ratio & {$[-]$} \\
$\tau_{t r}$ & Transmission gear ratio & {$\left[\mathrm{rad} \mathrm{s}^{-1}\right]$} \\
$\omega_{e}$ & Engine speed & {$\left[\mathrm{rad} \mathrm{s}^{-1}\right]$} \\
$\omega_{f}$ & Front axle angular velocity & \\
$\omega_{r}$ & Rear axle angular velocity & \\
& &
\end{tabular}

The power delivery efficiency (Eq. 16) is defined as:

$\eta_{T}=\frac{F_{D P} v}{M_{e} \omega_{e}}$

accounting for the first equation in the system of equations (1) and considering that, according to Eq. (2), $v=\omega_{f} r_{f}\left(1-s_{f}\right)=\omega_{r} r_{r}\left(1-s_{r}\right)$, Eq. (A1) can be manipulated as follows:

$\eta_{T}=\frac{\left(H_{f}+H_{r}\right) v}{M_{e} \omega_{e}}=\frac{H_{f} \omega_{f} r_{f}\left(1-s_{f}\right)+H_{r} \omega_{r} r_{r}\left(1-s_{r}\right)}{M_{e} \omega_{e}}$.

Further manipulation of Eq. (A2) yields: 


$$
\begin{aligned}
& \eta_{T}=\frac{H_{f} \omega_{f} r_{f}+H_{r} \omega_{r} r_{r}}{H_{f} \omega_{f} r_{f}+H_{r} \omega_{r} r_{r}} \frac{H_{f} \omega_{f} r_{f}\left(1-s_{f}\right)+H_{r} \omega_{r} r_{r}\left(1-s_{r}\right)}{M_{e} \omega_{e}}= \\
& =\frac{H_{f} \omega_{f} r_{f}+H_{r} \omega_{r} r_{r}}{M_{e} \omega_{e}} \frac{H_{f} \omega_{f} r_{f}+H_{r} \omega_{r} r_{r}-H_{f} \omega_{f} r_{f} s_{f}-H_{r} \omega_{r} r_{r} s_{r}}{H_{f} \omega_{f} r_{f}+H_{r} \omega_{r} r_{r}}= \\
& =\frac{H_{f} \omega_{f} r_{f}+H_{r} \omega_{r} r_{r}}{M_{e} \omega_{e}}\left(1-\frac{H_{f} \omega_{f} r_{f} s_{f}+H_{r} \omega_{r} r_{r} s_{r}}{H_{f} \omega_{f} r_{f}+H_{r} \omega_{r} r_{r}}\right) .
\end{aligned}
$$

Rephrasing Eq. (2) to express the term $\omega_{f} r_{f}$ allows further manipulation of the term inside the parenthesis in Eq. (A3):

$$
\begin{aligned}
& \eta_{T}=\frac{H_{f} \omega_{f} r_{f}+H_{r} \omega_{r} r_{r}}{M_{e} \omega_{e}}\left(1-\frac{H_{f} \frac{1-s_{r}}{1-s_{f}} \omega_{r} r_{r} s_{f}+H_{r} \omega_{r} r_{r} s_{r}}{H_{f} \frac{1-s_{r}}{1-s_{f}} \omega_{r} r_{r}+H_{r} \omega_{r} r_{r}}\right)= \\
& =\frac{H_{f} \omega_{f} r_{f}+H_{r} \omega_{r} r_{r}}{M_{e} \omega_{e}}\left(1-\frac{\left(1-s_{r}\right) H_{f} s_{f}+\left(1-s_{f}\right) H_{r} s_{r}}{\left(1-s_{r}\right) H_{f}+\left(1-s_{f}\right) H_{r}}\right) .
\end{aligned}
$$

Through the definition of pull distribution ratio it is possible to write:

$$
\begin{aligned}
& H_{f}=F_{D P}\left(1-K_{P}\right) \\
& H_{r}=F_{D P} K_{P} .
\end{aligned}
$$

(A6)

By means of Eqs. (A5)-(A6), Eq. (A4) can be further manipulated:

$$
\begin{aligned}
& \eta_{T}=\frac{H_{f} \omega_{f} r_{f}+H_{r} \omega_{r} r_{r}}{M_{e} \omega_{e}}\left(1-\frac{\left(1-s_{r}\right) s_{f} F_{D P}\left(1-K_{P}\right)+\left(1-s_{f}\right) s_{r} F_{D P} K_{P}}{\left(1-s_{r}\right) F_{D P}\left(1-K_{P}\right)+\left(1-s_{f}\right) F_{D P} K_{P}}\right)= \\
& =\frac{H_{f} \omega_{f} r_{f}+H_{r} \omega_{r} r_{r}}{M_{e} \omega_{e}}\left(1-\frac{\left(1-s_{r}\right) s_{f}\left(1-K_{P}\right)+\left(1-s_{f}\right) s_{r} K_{P}}{\left(1-s_{r}\right)\left(1-K_{P}\right)+\left(1-s_{f}\right) K_{P}}\right)=\frac{H_{f} \omega_{f} r_{f}+H_{r} \omega_{r} r_{r}}{M_{e} \omega_{e}}\left(1-\frac{s_{f}-s_{f} s_{r}-s_{f} K_{P}+s_{r} K_{P}}{1-s_{r}+s_{r} K_{P}-s_{f} K_{P}}\right)= \\
& =\frac{H_{f} \omega_{f} r_{f}+H_{r} \omega_{r} r_{r}}{M_{e} \omega_{e}}\left(1-\frac{s_{f}\left(1-s_{r}\right)-\left(s_{f}-s_{r}\right) K_{P}}{\left(1-s_{r}\right)-\left(s_{f}-s_{r}\right) K_{P}}\right) .
\end{aligned}
$$

The term inside the parenthesis in Eq. (A7) is the slip efficiency of the vehicle: 
$\eta_{S}=1-\frac{s_{f}\left(1-s_{r}\right)-\left(s_{f}-s_{r}\right) K_{P}}{\left(1-s_{r}\right)-\left(s_{f}-s_{r}\right) K_{P}}$

Eq. (A8) also allows to identify the vehicle slip:

$s=\frac{s_{f}\left(1-s_{r}\right)-\left(s_{f}-s_{r}\right) K_{P}}{\left(1-s_{r}\right)-\left(s_{f}-s_{r}\right) K_{P}}$.

Rephrasing Eq. (4) and considering the fourth equation in the system of equations (6), the following equations can be obtained:

$$
\begin{aligned}
& \omega_{f} r_{f}=K_{W} \tau_{d} \frac{\omega_{e}}{\tau_{t r}} r_{r} \\
& \omega_{r} r_{r}=\frac{\omega_{e}}{\tau_{t r}} r_{r} .
\end{aligned}
$$

Using Eqs. (A8), (A10) and (A11), Eq. (A7) becomes:

$$
\eta_{T}=\frac{H_{f} K_{W} \frac{\tau_{d}}{\tau_{t r}} r_{r}+H_{r} \frac{r_{r}}{\tau_{t r}}}{M_{e}} \eta_{S}
$$

Accounting for the first and the third equation in the system of equations (6), the following expression for $M_{e}$ can be obtained:

$M_{e}=\frac{M_{r}+\tau_{d} M_{f}}{\tau_{t r} \eta_{t r}}$

By means of Eq. (A13), Eq. (A12) becomes:

$\eta_{T}=\frac{H_{f} K_{W} \tau_{d} r_{r}+H_{r} r_{r}}{M_{r}+\tau_{d} M_{f}} \eta_{t r} \eta_{S}=\frac{H_{f} K_{W} \tau_{d}+H_{r}}{\frac{\tau_{d}}{r_{r}} M_{f}+\frac{M_{r}}{r_{r}}} \eta_{S} \eta_{t r}$

From Eq. (4) and exploiting the notion of front-to-rear ratio of kinetic rolling radii, the following are obtained:

$K_{W} \tau_{d}=L+1$

(A15)

$\frac{\tau_{d}}{r_{r}}=\frac{L+1}{r_{f}}$. 
Using Eqs. (A15) and (A16), Eq. (A14) becomes:

$\eta_{T}=\frac{H_{f}(L+1)+H_{r}}{\frac{M_{f}}{r_{r}}(L+1)+\frac{M_{r}}{r_{r}}} \eta_{S} \eta_{t r}$.

The first term in Eq. (A16) represents the motion efficiency of the vehicle:

$\eta_{M}=\frac{H_{f}(L+1)+H_{r}}{\frac{M_{f}}{r_{f}}(L+1)+\frac{M_{r}}{r_{r}}}$.

Finally, using Eq. (A18), the power delivery efficiency of a two-axle wheel-drive vehicle can be expressed as:

$\eta_{T}=\eta_{M} \eta_{S} \eta_{t r}$ 